\title{
Endogenization of Household Consumption in the Expanded Input-Output Model
}

\author{
E. A. Edinak ${ }^{a}$ * , A. R. Sayapova ${ }^{a}$, and A. A. Shirov ${ }^{a}$ \\ ${ }^{a}$ Institute of Economic Forecasting, Russian Academy of Sciences, Moscow, Russia \\ *e-mail: edinak_e@mail.ru
}

Received August 25, 2021; revised August 30, 2021; accepted September 6, 2021

\begin{abstract}
The article examines the relationship between the level of demand of income groups of the population and labor income. The influence of demand of various income groups of the population on production parameters has been investigated. As a calculation tool, input-output tables with an expanded total cost coefficient matrix by adding elements of wages and household consumption to it have been used. The conclusion has been substantiated that the growth of income and demand in low-income groups of the population has the greatest effect on production in the real sector, and in high-income groups of the population-on the products of the service sector. Large-scale sectors of the economy have been identified, the activities of which are most influenced by the demand of certain income groups, taking into account the induced effects that form in the economy. It has been noted that the growth in demand in low-income groups of the population is most reflected in the incomes of high-income groups of the population. It has been shown that even relatively modest structural shifts in the volume of wages by decile groups can lead to tangible structural and total changes in output. The analysis of the impact on production volumes of changes in the qualification structure of employment, reflecting smaller differences in the response of sectors of the economy to changes in demand of different qualification groups of workers than income groups, has been carried out.
\end{abstract}

Keywords: labor income, wages, income differentiation of the population, household consumption, qualification structure of employment, input-output tables, structural changes, economic growth

DOI: $10.1134 /$ S1075700722010063

Introduction. The economic recovery after the crisis caused by the coronavirus pandemic has exacerbated the range of issues related to the main factors of growth in the Russian economy. To improve the rate and quality of economic growth, it is necessary to seize a wide range of opportunities. This is an increase in the rate of accumulation of fixed capital, an increase in the contribution of state consumption to economic dynamics, and an activation of the structural component of economic dynamics. But, according to our estimates, household consumption has the greatest potential, which now forms about $50 \%$ of Russian GDP.

Negative dynamics of real incomes of the population in 2013-2020 became a significant restriction on the growth of population demand not only during this period, but also in the medium term. After the acute phase of the coronavirus crisis, against the background of the stabilization of the situation on the labor market, there is a relatively slow recovery of incomes of the population, which is determined by the postcrisis model of business behavior, as well as the gradual tightening of budget and monetary policies. The growth in consumption of the population in 2021 was determined, first of all, by the effect of deferred demand and restrictions associated with outbound tourism. However, as these factors are exhausted, consumer demand will be largely determined by fundamental structural factors, the main of which are high income differentiation of the population and uneven income dynamics by population groups $[1,2]$. For the period of 2013-2020, the incomes of the tenth-group households, the richest one, increased by about $12 \%$, while those of all other income groups decreased, and to a greater extent-of the poorest Russian families. In this regard, we are talking about restrictions on demand, which affect not only the volume of consumption, but also its quality. Risks are growing that, in the context of high inflation for food and nonfood products, the less well-off strata of the population will be forced to replace high-quality products with cheaper ones with poorer quality characteristics.

With varying degrees of detail, the identified problems are widely discussed within the framework of the general economic discussion in the country. However, what remains less illuminated is the fact that low growth rates, as well as the "poor" structure of household consumption (HC), limit the growth potential of the economy as a whole, and hence the growth of labor income. In this regard, the system of interactions in the contour "low incomes of the population-limitation of the growth of volumes and changes in the qual- 
ity of $\mathrm{HC}$-low rates of economic growth-low incomes of the population" requires a more detailed study.

\section{TOOLS}

A comprehensive study of the relationship between the income of the population, the volume and quality of $\mathrm{HC}$ and economic growth presupposes the availability of appropriate tools that reflect interactions in the modern economy. For calculations at the macroeconomic level, the most suitable tool is a symmetric input-output table (IOT)-the interindustry balance-which combines elements of gross value added (GVA), including labor income, and elements of final demand, including HC. It is known that the static model of the input-output balance has a high analytical value, including the Leontief matrix (a matrix of total costs or total needs), the elements of which link the costs of the $i$ th product per unit of final demand of the $j$ th product [3]. The multipliers calculated on this basis are actively used in assessing various macroeconomic effects arising from the exogenous growth of the final demand for any product or service [4], for example, multipliers of production costs, government spending, tax, investment multipliers, coefficients of total labor costs $[5,6]$

In the classical form, the total cost coefficient matrix is calculated on the basis of intermediate flows - the elements of the first quadrant of the IOand has a dimension that coincides with the number of industries taken into account in the IO. Meanwhile, the dimension of the Leontief matrix can be expanded by including individual elements of the second and third quadrants (this process in the scientific literature is called endogenization) [7-9].

In general, endogenization can be performed in relation to various functional elements of final demand and GVA. But taking into account the tasks set in the study, for a more complete understanding of the relationship between final demand and labor incomes of the population, the IO model is closed specifically for the final consumption of households and wages. Such endogenization occurs most often in the scientific literature due to the fact that household consumption is the largest element of final demand and is directly related to wages.

Closing the IO model by household final consumption can be performed using the following wellknown scheme. The growth of final demand imposes corresponding requirements on the output of industries for its provision-outputs are also growing, and incomes of the population are growing accordingly. The increased incomes of the population, in turn, increase the consumption of households, which leads to an increase in output, etc., up to a weakening of the process. This process, therefore, forms new volumes of outputs due to direct, indirect (taking into account intersectoral interactions) and induced (taking into account the redistribution of newly emerged income) effects. These outputs are the same as those calculated based on the expanded IO model. In addition, the wages corresponding to the induced releases also occur based on the solution of the expanded model. A sufficiently detailed description of the expanded IO model and the proof of the coincidence of the results of calculations of induced outputs by the original model and those by the expanded model for the case of expanding the 1st quadrant of the standard IO table by one column and by one row are given in [10].

Let us briefly consider the case of expanding the 1st quadrant of the original IO table by $r$ columns and $r$ rows. For this purpose, we will somewhat transform the standard symmetric input-output table: in Table 1 , in the 2nd quadrant, the endogenized elements of final demand are separately distinguished, in the 3rd quadrant the corresponding elements of value added (for example, in the 3rd quadrant there are decile groups in wages, in the 2nd quadrant the corresponding groups of household consumption groups). The remaining elements of final demand and value added are categorized as "Other final demand" and "Other added value."

Let us introduce the notation:

$A$ is the matrix with elements $a_{i j}=\frac{x_{i j}}{X_{j}}$, where $x_{i j}$ is the intermediate flows from the $i$ th industry to the $j$ th industry, $X_{j}$ is the $j$ th industry output, $X$ is the vector with elements $X_{j}, B=(I-A)^{-1}$.

$V$ is the matrix with elements $V_{k j}=\frac{V_{k j}}{X_{j}}$, where $V_{k j}$ is the volume of the $k$ th category of value added in the $j$ th industry (for example, the wages of the $k$ th decile group in the $j$ th industry).

$H$ is the matrix with elements $h_{i k}=\frac{Y_{i k}}{V_{k}}$, where $V_{k}=\sum_{j=1}^{n} V_{k j}, \tilde{V}$ is the column vector with elements $V_{k}$ (for example, the salary of the $k$ th decile group).

$$
Y=\left(\begin{array}{c}
\sum_{k=1}^{r} Y_{1 k} \\
\vdots \\
\sum_{k=1}^{r} Y_{n k}
\end{array}\right) \text {, where } Y_{i k} \text { is the volume of the } k \text { th }
$$
element of the final demand for products of the $i$ th industry (for example, the volume of consumption of the $i$ th product by the $k$ th group of households, provided by the $k$ th decile wage group).

$z_{j}$ is the other value added of the $j$ th industry.

$f$ is the vector of other final demand with elements $f_{i}$, i.e., the vector of final demand minus the vector $Y$.

Let us consider in more detail the process of the formation of induced effects due to the initial impulse of growth of other final demand for $\Delta f$. At the first stage of the propagation of induced effects, we obtain an increase in outputs: 
Table 1. Expanded symmetric input-output table

\begin{tabular}{|c|c|c|c|c|c|c|c|c|}
\hline Industry & 1 & $\cdots$ & $n$ & \multicolumn{3}{|c|}{ Endogenized elements of final demand } & \multirow{2}{*}{$\begin{array}{c}\begin{array}{c}\text { Other final } \\
\text { demand }\end{array} \\
f_{1}\end{array}$} & \multirow{2}{*}{$\frac{\text { Output }}{X_{1}}$} \\
\hline 1 & $x_{11}$ & $\ldots$ & $x_{1 n}$ & $Y_{11}$ & $\ldots$ & $Y_{1 r}$ & & \\
\hline$\vdots$ & $\vdots$ & $\ddots$ & & $\vdots$ & $\ddots$ & $\vdots$ & $\vdots$ & $\vdots$ \\
\hline$n$ & $x_{n 1}$ & $\ldots$ & $x_{n n}$ & $Y_{n 1}$ & $\ldots$ & $Y_{n r}$ & $f_{n}$ & $X_{n}$ \\
\hline \multirow{3}{*}{$\begin{array}{l}\text { Endoge- } \\
\text { nized value } \\
\text { added ele- } \\
\text { ments }\end{array}$} & $V_{11}$ & $\ldots$ & $V_{1 n}$ & & & & & \\
\hline & $\vdots$ & $\ddots$ & & & & & & \\
\hline & $V_{r 1}$ & $\ldots$ & $V_{r n}$ & & & & & \\
\hline $\begin{array}{l}\text { Other value } \\
\text { added }\end{array}$ & $z_{1}$ & $\cdots$ & $z_{n}$ & & & & & \\
\hline Output & $X_{1}$ & $\ldots$ & $X_{n}$ & & & & & \\
\hline
\end{tabular}

$$
\Delta X_{1}=B \Delta f
$$

Accordingly, the increase in outputs is translated into an increase in value added elements in the form $V \Delta X_{1}=V B \Delta f$. In turn, an increase in the elements of value added initiates an increase in the elements of final demand: $H V \Delta X_{1}=H V B \Delta f$. Further, with a new increase in the elements of final demand, the process is repeated, etc.

Let us denote by $m$ the numerical stage of the process of propagation of induced effects. Then:

$$
\Delta X_{m}=B H V \Delta X_{m-1}(m \geq 2) .
$$

Therefore,

$$
\begin{gathered}
\Delta X_{m}=(B H V)^{m-1} B \Delta f \\
=B H(V B H)^{m-2} V B \Delta f=B H L^{m-2} V B \Delta f,
\end{gathered}
$$

where $L=V B H$.

Thus,

$$
\begin{aligned}
& \Delta X=\sum_{m=1}^{\infty} \Delta X_{m}=B \Delta f+B H\left(\sum_{m=2}^{\infty} L^{m-2}\right) V B \Delta f . \\
& \sum_{m=2}^{\infty} L^{m-2}=I+L+L^{2}+\ldots+L^{n} \ldots=(I-L)^{-1} .
\end{aligned}
$$

It is known that series (4) converges if the norm of the matrix $L N(L)<1 .{ }^{1}$ We will give the proof for $N(L)<1$ later. For now, let us prove that the result

$$
\Delta X=\sum_{m=1}^{\infty} \Delta X_{m}=B \Delta f+B H(I-L)^{-1} V B \Delta f
$$

can be obtained on the basis of the expanded IO model, which includes additional $r$ columns and $r$ rows in the 1st quadrant.

\footnotetext{
${ }^{1}$ For example, the proof can be found in the source [3].
}

In matrix form, the extended IOB model looks as follows:

$$
\left[\begin{array}{cc}
I-A & -H \\
-V & I
\end{array}\right] \bar{X}=\bar{f},
$$

where $\bar{X}=\left[\begin{array}{c}X \\ \tilde{X}\end{array}\right], \bar{f}=\left[\begin{array}{l}f \\ 0\end{array}\right], 0$ is the zero-order vector $r x 1, \tilde{X}$ is the order vector $r x 1$, corresponding to the "outputs" of new industries as part of the expanded IO model.

$$
\bar{X}=\left[\begin{array}{cc}
I-A & -H \\
-V & I
\end{array}\right]^{-1} \bar{f} .
$$

Relation (7) is also valid for incremental indicators:

$$
\Delta \bar{X}=\left[\begin{array}{cc}
I-A & -H \\
-V & I
\end{array}\right]^{-1} \Delta \bar{f} .
$$

Then, according to the algebra of block matrices, if the original matrix is $\left[\begin{array}{cc}E & F \\ G & H\end{array}\right]$ and we denote its inverse matrix by $\left[\begin{array}{ll}S & T \\ U & V\end{array}\right]$, then $S=E^{-1}(I-F U), T=-E^{-1} \mathrm{FV}$, $U=-V G E^{-1}, V=\left(H-G E^{-1} F\right)^{-1} \cdot 2$

Assuming that

$$
\left[\begin{array}{cc}
I-A & -H \\
-V & I
\end{array}\right]^{-1}=\left[\begin{array}{cc}
S & T \\
U & V
\end{array}\right]
$$

we obtain:

\footnotetext{
${ }^{2}$ See the source [11].
} 


$$
\begin{gathered}
{\left[\begin{array}{cc}
I-A & -H \\
-V & I
\end{array}\right]^{-1}} \\
=\left[\begin{array}{cc}
B+B H(I-L)^{-1} V B & B H(I-L)^{-1} \\
(I-L)^{-1} V B & (I-L)^{-1}
\end{array}\right] .
\end{gathered}
$$

Hence

$$
\Delta \bar{X}=\left[\begin{array}{c}
\left(B+B H(I-L)^{-1} V B\right) \Delta f \\
(I-L)^{-1} V B \Delta f
\end{array}\right] .
$$

The first line is coincident with $\Delta X$ by formula (5). Let us prove that

$$
\widetilde{\Delta X}=(I-L)^{-1} V B \Delta f=\Delta \tilde{V} .
$$

The balanced values of the induced increases in the elements of value added and final demand according to the $n$-industry model should obey the ratio:

$$
\Delta \tilde{V}=V(I-A)^{-1}(H \Delta \tilde{V}+\Delta f) .
$$

Hence

$$
\begin{gathered}
\left.\Delta \tilde{V}=\left(I-V(I-A)^{-1} H\right)^{-1} V(I-A)^{-1}\right) \Delta f \\
=(I-V B H)^{-1} V B \Delta f=(I-L)^{-1} V B \Delta f,
\end{gathered}
$$

which coincides with formula (11).

Thus, the increments in outputs and value-added elements calculated according to the $n$-industry model as induced by the initial growth in other final demand, and the increments in outputs calculated using the static expanded IO model, coincide. ${ }^{3}$

Let us get back to the proof for $N(L)<1$. Note that the number

$$
N(L)=\max _{j} \sum_{i=1}^{n}\left|l_{i j}\right|
$$

is the matrix norm $L^{4}$. Thus, if we prove that the totals of the columns of nonnegative ${ }^{5}$ matrix $L=V B H$ are less than 1 , then this implies $N(L)<1$. First, we prove that the totals of the columns of the product $V B$, equal to $i_{r} V B$, are less than $1\left(i_{r}\right.$ is the unit row vector of dimension $1 \times r$ ). Row vector $i_{r} V$-the total shares of the $r$ categories of value added under consideration in the outputs (for example, the total shares of wages of decile groups)-we denote by $D^{w}$. Let us denote by $D$ the row vector $(1 \times n)$ of the share of value added in industry issues. It is known that $D B=i_{n}\left(D=i_{n}(I-A), \quad B=(I-A)^{-1}, \quad\right.$ then

\footnotetext{
${ }^{3}$ Another version of the proof of the coincidence of these results can be found in the source [12].

${ }^{4}$ For the possibility of determining the matrix norm by (14), see, for example, the source [13].

5 The elements of the matrix $V, B, H$ are nonnegative according to their economic meaning, therefore, the elements of the products of these matrices are nonnegative.
}

$\left.D B=i_{n}(I-A)(I-A)^{-1}=i_{n}\right)$, where $i_{n}$ is unit row vector of dimension $1 \times n$. In turn, all elements of the vector $D^{w}$ are less than the corresponding elements of the vector $D$, respectively $D B-D^{w} B>0$, where 0 is zero vector. Hence $i_{n}>D^{w} B$, therefore, the totals of the columns of the product $V B$ are less than 1 . Next, we prove that the totals of the columns of the product $V B H$ are less than 1, i.e., $i_{r} V B H<i_{r}(15)$. The totals of the columns of the matrix $H: \sum_{i=1}^{n} h_{i k}$ are less than 1, since the elements $h_{i k}$ are defined as $\frac{Y_{i k}}{V_{k}}$, in turn, $\sum_{i=1}^{n} Y_{i k}<V_{k}\left(\sum_{i=1}^{n} Y_{i k}\right.$ is the part of final demand provided by an of value added element $V_{k}$ ). Let us denote by $c_{j}$ row vector elements $i_{r} V B$ of the dimension $1 \times n$. Then each element of the row vector $i_{r} V B H$ is $\sum_{i=1}^{n} c_{i} h_{i k}$, where $\sum_{i=1}^{n} h_{i k}<1$ and $c_{i}<1, i=1, \ldots, n$, whence it follows that $\sum_{i=1}^{n} c_{i} h_{i k}<1$. Therefore, the totals of the columns of the matrix $L=V B H$ are less than 1 and $N(L)<1$, which proves the convergence of the series (4).

As noted in the introduction, a significant factor limiting the growth of population demand and changes in its quality is the differentiation of the population by income. In this regard, the peculiarity of this study is that the endogenization of the vectors of household consumption and labor income of the population (wages) is carried out taking into account their differentiation by decile groups. The possibility of taking into account the structure of consumption of different decile groups, as well as labor incomes of different qualification groups (occupation groups), was previously proposed and implemented in the article [14]. In this study, the vector of the wage fund is differentiated by decile groups of employees and is estimated based on the data of the Rosstat bulletin "Information on the distribution of the number of employees by wages for 2017" and data on wages by industry in the aggregated IOT for 2017.

The coefficients of the total costs (requirement) of the expanded input-output model, taking into account the differentiation by decile groups of labor income and household consumption, contain direct, indirect, and induced ${ }^{6}$ expenses. The total cost coefficient matrix of the expanded input-output model can be conditionally divided into four blocks. Elements of the first, classical block, $n \times n$, show the total costs of the $i$ th industry per unit of the $j$ th final demand. The difference from the full cost coefficients of the classical model is that, in addition to direct and indirect costs, they include induced costs. The second block of dimension $n \times r$ contains the coefficients of the total

\footnotetext{
${ }^{6}$ Induced costs reflect the costs incurred by the propagation effect of the initial impulse into final demand.
} 
Table 2. Coefficients of total requirement in output of industries per unit of consumer expenditures of decile groups of households

\begin{tabular}{l|c|c|c|c|c|c|c|c|c|c}
\hline \multirow{2}{*}{ Industry } & \multicolumn{7}{|c}{ Coefficients of total requirement by decile groups } \\
\cline { 2 - 10 } & 1 & 2 & 3 & 4 & 5 & 6 & 7 & 8 & 9 & 10 \\
\hline $\begin{array}{l}\text { Agriculture, forestry, hunting, } \\
\text { fishing, and fish farming }\end{array}$ & 0.1256 & 0.1206 & 0.1170 & 0.1116 & 0.1062 & 0.1019 & 0.0995 & 0.0944 & 0.0897 & 0.0726 \\
Manufacturing industries & 0.6319 & 0.6187 & 0.6109 & 0.5968 & 0.5800 & 0.5655 & 0.5625 & 0.5507 & 0.5433 & 0.5015 \\
$\begin{array}{l}\text { Electricity, gas and steam sup- } \\
\text { ply; air conditioning }\end{array}$ & 0.1404 & 0.1338 & 0.1301 & 0.1270 & 0.1227 & 0.1175 & 0.1128 & 0.1077 & 0.1026 & 0.0846 \\
Trade & 0.3374 & 0.3309 & 0.3272 & 0.3224 & 0.3142 & 0.3072 & 0.3058 & 0.2992 & 0.2954 & 0.2549 \\
Public administration and mil- & 0.0046 & 0.0045 & 0.0045 & 0.0044 & 0.0044 & 0.0043 & 0.0044 & 0.0043 & 0.0043 & 0.0039 \\
itary security, social security & & & & & & & & & & \\
Education & 0.0084 & 0.0097 & 0.0106 & 0.0129 & 0.0126 & 0.0132 & 0.0143 & 0.0150 & 0.0134 & 0.0084 \\
Activities in the field of health & 0.0120 & 0.0141 & 0.0163 & 0.0183 & 0.0180 & 0.0208 & 0.0220 & 0.0269 & 0.0289 & 0.0327 \\
and social services & & & & & & & & & & \\
Activities in the field of culture, & 0.0069 & 0.0075 & 0.0080 & 0.0087 & 0.0095 & 0.0097 & 0.0111 & 0.0121 & 0.0150 & 0.0117 \\
sports, leisure and entertain- & & & & & & & & & & \\
ment & & & & & & & & & & \\
\hline
\end{tabular}

Source: hereinafter in the tables, the authors' calculations.

requirements for the output of industries per unit of consumer expenditures ${ }^{7}$ of decile groups of households. The coefficients of the third block (of dimension $r \times n)$ show the increase in the wage fund of the $k$ th decile group of workers per unit of growth in the $j$ th final demand. The elements of the fourth block, of dimension $r \times r$, show a general increase (direct, indirect, and induced) in the wage fund of one decile group as a result of spending an additional unit of labor income by another decile group. The total cost coefficients of the fourth block in the source [11] are called "interrelational income multiplier." Thus, the article expands the input-output model by transferring differentiated wage lines from the 3 rd quadrant and the household consumption columns from the 2 nd quadrant to the 1st quadrant. This approach provides many opportunities to study the relationship between the incomes of various groups of the population, the impact of changes in the final demand differentiated by the structure on the outputs of industries and labor incomes of certain groups of the population.

Analysis of the coefficients of the expanded total cost matrix. Coefficients of the total needs for increasing the output of industries with an increase per unit of consumer spending of each of the groups of households (Table 2) are significantly differentiated by industry and, most importantly, by the level of income, which is due to their different consumption structure.

So, for example, the coefficient of total requirements for agricultural products for the 1st decile group is 0.1256 , and for the 10th decile group, 0.0726 . This

\footnotetext{
${ }^{7}$ Hereinafter, consumer expenditures are understood as those that are provided with primary income from labor activity.
}

difference is explained by the higher share of agricultural products in the structure of expenditures in the 1 st decile compared to the 10 th one $(5.3 \%$ vs. $1.9 \%)$. A similar picture is observed for the manufacturing and power industries. For such industries as "Activity of hotels and public catering enterprises," health care, culture and sports, the coefficients, on the contrary, increase with an increase in the number of the decile group due to the insufficient level of consumption of these goods by households belonging to the lower decile groups.

Attention is drawn to the situation in education, where the greatest demand for educational services is presented by the middle decile groups of households. It can be assumed that this is due to the active growth of paid educational services in the segments of secondary and higher education, focused on representatives of these income groups. The trade sector is more strongly influenced by the expenditures of the lower income groups of the population.

Analyzing the impact of changes in demand on production volumes (see Table 1), it can be noted, with some reservations, that an increase in costs in the lower decile groups will lead to an increase in demand and, accordingly, the need for production of products for the most part of the real sector of the economy, while a similar increase in spending in the upper decile groups will lead to an increase in demand and an increase in the supply of services. Of course, a long period of increase in real incomes in the lower decile groups will inevitably lead to a qualitative change in their consumption structure. However, this effect will be clearly observed in the long or medium term. In this regard, the lack of an implemented approach, due to 
Table 3. Coefficients of change in the wage fund by decile groups per unit of sectoral final demand

\begin{tabular}{|c|c|c|c|c|c|c|c|c|c|c|}
\hline \multirow{2}{*}{ Industries } & \multicolumn{10}{|c|}{ Coefficients of change in the wage fund by decile groups } \\
\hline & 1 & 2 & 3 & 4 & 5 & 6 & 7 & 8 & 9 & 10 \\
\hline $\begin{array}{l}\text { Agriculture, forestry, hunting, } \\
\text { fishing, and fish farming }\end{array}$ & 0.0076 & 0.0110 & 0.0137 & 0.0164 & 0.0192 & 0.0223 & 0.0261 & 0.0313 & 0.0397 & 0.0840 \\
\hline Manufacturing industries & 0.0089 & 0.0133 & 0.0166 & 0.0198 & 0.0231 & 0.0268 & 0.0315 & 0.0379 & 0.0485 & 0.1042 \\
\hline $\begin{array}{l}\text { Electricity, gas and steam supply; } \\
\text { air conditioning }\end{array}$ & 0.0099 & 0.0147 & 0.0184 & 0.0217 & 0.0254 & 0.0295 & 0.0349 & 0.0422 & 0.0544 & 0.1122 \\
\hline Trade & 0.0086 & 0.0129 & 0.0163 & 0.0195 & 0.0230 & 0.0269 & 0.0320 & 0.0389 & 0.0511 & 0.1226 \\
\hline $\begin{array}{l}\text { Public administration and mili- } \\
\text { tary security, social security }\end{array}$ & 0.0151 & 0.0230 & 0.0292 & 0.0353 & 0.0420 & 0.0501 & 0.0595 & 0.0710 & 0.0889 & 0.1724 \\
\hline Education & 0.0210 & 0.0292 & 0.0363 & 0.0444 & 0.0539 & 0.0636 & 0.0756 & 0.0922 & 0.1196 & 0.2332 \\
\hline $\begin{array}{l}\text { Activities in the field of health } \\
\text { and social services }\end{array}$ & 0.0183 & 0.0262 & 0.0326 & 0.0381 & 0.0445 & 0.0521 & 0.0621 & 0.0763 & 0.0999 & 0.1930 \\
\hline $\begin{array}{l}\text { Activities in the field of culture, } \\
\text { sports, leisure and entertainment }\end{array}$ & 0.0127 & 0.0182 & 0.0229 & 0.0271 & 0.0321 & 0.0378 & 0.0451 & 0.0559 & 0.0744 & 0.2099 \\
\hline
\end{tabular}

the fact that the model, when calculating induced effects, does not take into account the possibility of changing the structure of consumption of decile groups, does not fundamentally affect the results. In general, the obtained coefficients, even at the aggregate level, make it possible to assess how consumer demand affects the economy and possible shifts in the structure of production.

It is clear that the final demand in the economy, including from households, through changes in sectoral production volumes affects the change in the labor income of the population. Traditionally, to measure this effect, the hypothesis of a proportional change in the volume of GVA as a whole and its elements, including wages, in the structure of sectoral output is used (see, for example, [4]). In turn, the endogenization-based approach allows this effect to be assessed within an extended total cost matrix. Moreover, the primary data used in the article make it possible to analyze the influence of the sectoral final demand in the economy on the labor income of individual decile groups of workers.

Thus, the coefficients of the third block of the matrix show how the increase in the final demand of the jth industry will affect the wage fund of the $\mathrm{k}$ th decile group, taking into account direct, indirect, and induced effects. When analyzing them, the first thing to note is the high differentiation of the values of the coefficients between the first and tenth decile groups, which varies from 10.5 times (in the healthcare industry) to 16 times (professional, scientific, and technical activities). In other words, the growth of sectoral final demand leads to a more significant increase in labor incomes of the upper decile groups. It is interesting that the change in labor incomes of all decile groups is most sensitive to an increase in the final demand for products and services of three sectors: 1) public administration and military security, social security;
2) education; 3) activities in the field of health care and social services. For some decile groups, one can also note a significant influence of the final demand on the services of the industry, activities in the field of culture, sports, organization of leisure and entertainment (Table 3).

The indicated industries are characterized by the highest share of wages in the cost structure. It is indicative that in the structure of the final demand of all these industries, the share of government spending is high. In the sector of public administration and military security, social security, it reaches almost $100 \%$; in education, a little over $80 \%$; in health care, $70 \%$; in culture, sports, leisure and entertainment, 54\%.

As for household expenditures, if the change in the output of the first sector is largely determined by the consumption expenditures of the lower decile groups, in education, as already mentioned, by the medium ones, then the output of the health sector depends on the effective demand of the upper decile groups.

The effect of the growth of final demand in agriculture (the share of household expenditures in which is $71 \%$ ), or, for example, in the sector of providing electricity, gas and steam; air conditioning $(85 \%$, respectively) is rated lower across all decile groups compared to the four industries listed above, while the gap between changes in labor income in the extreme decile groups remains high.

Estimates of the interrelation income multiplier. Estimates of the multipliers of interrelated incomes (Table 4) show a decrease in the intensity of the interdependence of incomes of decile groups as the distance between the groups increases. For example, an increase in consumer spending of the 2 nd decile group per unit leads to an increase (direct, indirect, and induced) in the wages fund of the 1st decile group by 0.0067 , and the same increase in consumer spending of the 10th decile group by 0.0056 . 
Table 4. Interrelational income multiplier of decile groups of households

\begin{tabular}{c|c|c|c|c|c|c|c|c|c|c}
\hline Group number & 1 & 2 & 3 & 4 & 5 & 6 & 7 & 8 & 9 & 10 \\
\hline 1 & 1.0068 & 0.0067 & 0.0067 & 0.0066 & 0.0065 & 0.0064 & 0.0065 & 0.0064 & 0.0064 & 0.0056 \\
2 & 0.0101 & 1.0100 & 0.0099 & 0.0099 & 0.0097 & 0.0096 & 0.0096 & 0.0095 & 0.0095 & 0.0084 \\
3 & 0.0128 & 0.0126 & 1.0125 & 0.0124 & 0.0122 & 0.0121 & 0.0121 & 0.0120 & 0.0119 & 0.0105 \\
4 & 0.0153 & 0.0150 & 0.0149 & 1.0149 & 0.0146 & 0.0144 & 0.0145 & 0.0143 & 0.0143 & 0.0126 \\
5 & 0.0180 & 0.0177 & 0.0176 & 0.0175 & 1.0172 & 0.0170 & 0.0171 & 0.0169 & 0.0168 & 0.0148 \\
6 & 0.0210 & 0.0207 & 0.0206 & 0.0205 & 0.0201 & 1.0199 & 0.0200 & 0.0198 & 0.0197 & 0.0173 \\
7 & 0.0249 & 0.0245 & 0.0244 & 0.0243 & 0.0239 & 0.0236 & 1.0237 & 0.0235 & 0.0233 & 0.0206 \\
8 & 0.0303 & 0.0298 & 0.0297 & 0.0296 & 0.0291 & 0.0287 & 0.0289 & 1.0286 & 0.0284 & 0.0251 \\
9 & 0.0394 & 0.0389 & 0.0387 & 0.0385 & 0.0379 & 0.0374 & 0.0376 & 0.0373 & 1.0371 & 0.0327 \\
10 & 0.0884 & 0.0871 & 0.0867 & 0.0863 & 0.0850 & 0.0839 & 0.0844 & 0.0836 & 0.0833 & 1.0732 \\
\hline
\end{tabular}

In other words, an increase in consumer spending per unit in the 10th decile group causes a weaker response in the payroll of the 1st decile group of workers than a similar increase in consumer spending in the lower decile groups of households. Apparently, this is due to the lower specific demand for most goods from the consumers of the 10th decile group, and as a result, the lowest response in the payroll. Such a decrease in the intensity of the interdependence of income is typical for all decile groups and, on average, for the 1st and 10 th groups is $20 \%$.

At the same time, the multiplier effect of consumer spending in the 1st decile increases as the group number increases. For example, an increase in consumer spending of the 1st decile group of households per unit leads to an increase in the payroll of the 2 nd decile group by 0.0101 and an increase in the payroll of the 10 th decile group by 0.0884 . Thus, with the existing level of stratification of the population in terms of income and the prevailing structure of consumption, each additional ruble of consumer spending only leads to an increase in the gap between incomes. Here we can speculate that, given the existing structure of imbalances in terms of income, the richest households may be interested in an increase in demand from the less wealthy strata of the population. This may be one of the arguments in favor of a more intensive redistribution of primary income in favor of low-income groups of the population.

Assessment of the effects of structural changes in wages. The endogenization of household consumption in the expanded input-output model makes it possible to measure the influence of the employment structure not only on the dynamics of production, but also on its structure. Consider a conditional scenario of the redistribution of funds for wages in favor of the 1st decile group, assuming an increase in payroll by 1.5 times due to a proportional decrease in funds for wages in other decile groups, while maintaining the sectoral payroll volumes (the line of wages in the input-output symmetric table).

Other final demand also remains at the basic level, including government expenditures on individual and collective goods and services, expenditures of nonprofit organizations serving households, gross capital formation, net exports, and the rest of household con-

Table 5. Scenario of a 1.5 -fold increase in wages in the 1 st decile group: change in outputs to the 2017 baseline, $\%$

\begin{tabular}{l|c}
\hline \multicolumn{1}{c|}{ Industry } & $\begin{array}{c}\text { Change } \\
\text { in outputs }\end{array}$ \\
\hline Agriculture, forestry, hunting, fishing, and fish & 0.20 \\
farming & \\
Mining & 0.04 \\
Manufacturing industries & 0.07 \\
Electricity, gas and steam supply; air condi- & 0.15 \\
tioning & \\
Water supply; water disposal, organization of & 0.14 \\
waste collection and disposal, activities to elim- & \\
inate pollution & \\
Construction & 0.01 \\
Wholesale and retail trade; repair of motor & 0.08 \\
vehicles and motorcycles & 0.03 \\
Transport and storage & -0.30 \\
Activities of hotels and catering enterprises & 0.13 \\
Information and communication activities & 0.02 \\
Financial and insurance activities & 0.24 \\
Real estate activities & 0.03 \\
Professional, scientific and technical activities & 0.03 \\
Administrative activities and related additional \\
services & -0.03 \\
Public administration and military security, & -0.11 \\
social security & -0.09 \\
Education & \\
Activities in the field of health and social services & \\
and entertainment & \\
\hline Provision of other types of services & \\
\hline
\end{tabular}

Vol. 33 No. $1 \quad 2022$ 


\begin{tabular}{|c|c|c|c|c|c|c|c|c|c|}
\hline  & $\sigma$ & 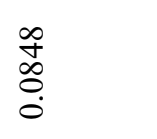 & $\begin{array}{l}\text { oे } \\
\text { in } \\
0\end{array}$ & $\begin{array}{l}0 \\
0 \\
0 \\
0\end{array}$ & $\begin{array}{l}\tilde{\hat{n}} \\
\stackrel{0}{0}\end{array}$ &  & $\stackrel{\partial}{\overrightarrow{0}}$ & $\begin{array}{l}\hat{\tilde{\sigma}} \\
\text { Oे }\end{array}$ & $\begin{array}{l}\stackrel{n}{0} \\
\stackrel{0}{0} \\
0\end{array}$ \\
\hline 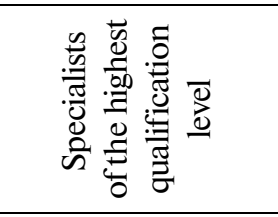 & $\infty$ & $\begin{array}{l}\tilde{\kappa} \\
\hat{o} \\
0\end{array}$ & $\begin{array}{l}\vec{f} \\
\text { nn? } \\
\text { on }\end{array}$ & $\begin{array}{l}\text { Oे } \\
0 \\
0\end{array}$ & $\begin{array}{l}0 \\
\stackrel{6}{0} \\
0\end{array}$ & $\begin{array}{l}\text { } \\
\stackrel{\tilde{\sigma}}{0} \\
\stackrel{0}{0}\end{array}$ & $\begin{array}{l}\frac{\tilde{f}}{\partial} \\
\stackrel{0}{0}\end{array}$ & $\begin{array}{l}\infty \\
\text { Oें } \\
\text { Oें }\end{array}$ & $\begin{array}{l}\vec{m} \\
\stackrel{0}{0} \\
0\end{array}$ \\
\hline 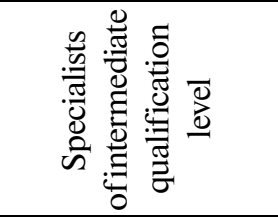 & n & $\begin{array}{l}\overrightarrow{\widehat{\Xi}} \\
\stackrel{0}{0}\end{array}$ & $\begin{array}{l}\bar{\sigma} \\
\text { n? } \\
0\end{array}$ & $\begin{array}{l}\stackrel{N}{\Xi} \\
0\end{array}$ & $\begin{array}{l}n \\
\stackrel{n}{0} \\
0\end{array}$ & $\begin{array}{l}\stackrel{\text { Iิ }}{\hat{\delta}} \\
\text { o. }\end{array}$ & $\begin{array}{l}\infty \\
\stackrel{0}{0} \\
0\end{array}$ & $\begin{array}{l}\stackrel{m}{\vec{d}} \\
\stackrel{0}{0}\end{array}$ & $\begin{array}{l}\stackrel{\partial}{0} \\
\stackrel{0}{0}\end{array}$ \\
\hline 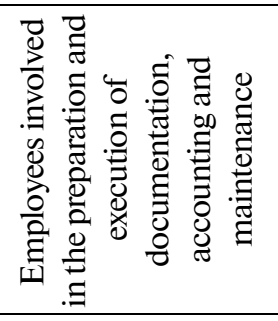 & 0 & $\begin{array}{l}\stackrel{+}{\circ} \\
\stackrel{0}{0}\end{array}$ & $\begin{array}{l}0 \\
0 \\
\infty \\
n \\
0\end{array}$ & $\begin{array}{l}\stackrel{\tilde{d}}{0} \\
0\end{array}$ & $\begin{array}{l}\hat{\hat{b}} \\
\stackrel{0}{0}\end{array}$ & $\begin{array}{l}\widetilde{\approx} \\
\text { ठิ } \\
\stackrel{0}{0}\end{array}$ & $\begin{array}{l}\vec{m} \\
\stackrel{0}{0} \\
0\end{array}$ & $\begin{array}{l}\vec{\infty} \\
\overrightarrow{0} \\
0\end{array}$ & $\begin{array}{l}\tilde{O} \\
\text { Oे. } \\
\text {. }\end{array}$ \\
\hline 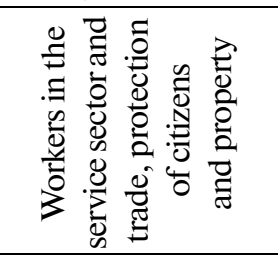 & in & $\begin{array}{l}\hat{O} \\
0\end{array}$ & $\begin{array}{l}0 \\
\text { Dे } \\
i \\
0\end{array}$ & 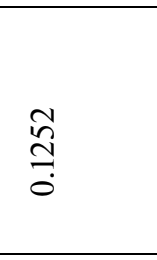 & $\begin{array}{l}\stackrel{0}{6} \\
\frac{0}{0}\end{array}$ & 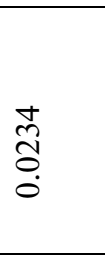 & $\begin{array}{l}\stackrel{\infty}{\Xi} \\
\stackrel{0}{0}\end{array}$ & $\begin{array}{l}\hat{\imath} \\
\stackrel{0}{0} \\
0\end{array}$ & $\begin{array}{l}\hat{\circ} \\
\dot{0} \\
\dot{0}\end{array}$ \\
\hline 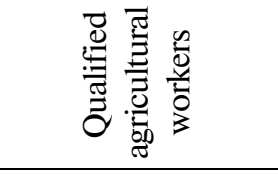 & $\nabla$ & 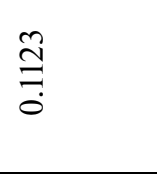 & $\begin{array}{l}\text { ț } \\
\hat{\sigma} \\
0\end{array}$ & $\begin{array}{l}\stackrel{0}{7} \\
\dddot{7}\end{array}$ & $\begin{array}{l}\stackrel{0}{0} \\
\stackrel{0}{0}\end{array}$ & 灾 & $\begin{array}{l}\tilde{O} \\
\stackrel{0}{0}\end{array}$ & $\begin{array}{l}\stackrel{0}{0} \\
\stackrel{0}{0}\end{array}$ & $\begin{array}{l}\text { oे } \\
\text { ठ } \\
0\end{array}$ \\
\hline 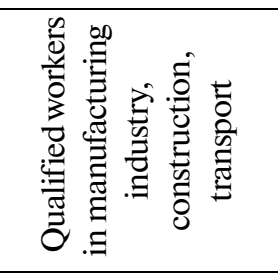 & $m$ & $\frac{\widetilde{\sigma}}{0}$ & $\begin{array}{l}\infty \\
\infty \\
0 \\
n \\
0\end{array}$ & $\begin{array}{l}+\underset{O}{O} \\
0\end{array}$ & $\frac{\stackrel{\circ}{G}}{0}$ & 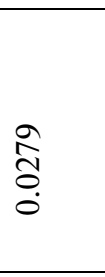 & $\stackrel{\text { fo }}{\stackrel{\sigma}{0}}$ & $\begin{array}{l}\stackrel{0}{a} \\
\stackrel{0}{0}\end{array}$ & $\begin{array}{l}\hat{0} \\
0 \\
0\end{array}$ \\
\hline 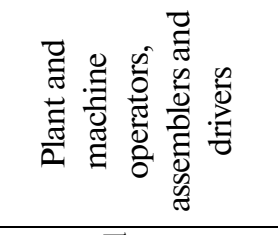 & $\sim$ & $\frac{\hat{\sigma}}{0}$ & $\begin{array}{l}\infty \\
\stackrel{n}{n} \\
0\end{array}$ & $\frac{0}{\dddot{T}}$ & $\begin{array}{l}\frac{1}{0} \\
0 \\
0\end{array}$ & 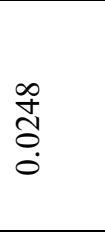 & $\begin{array}{l}\stackrel{+}{m} \\
\stackrel{0}{0} \\
0\end{array}$ & 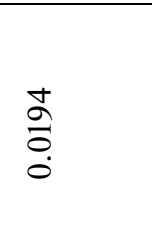 & $\begin{array}{l}\infty \\
\stackrel{8}{0} \\
\dot{0}\end{array}$ \\
\hline 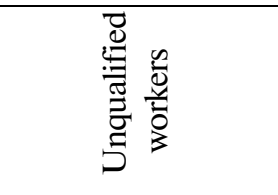 & - & $\begin{array}{l}\stackrel{+}{6} \\
\stackrel{0}{0}\end{array}$ & $\begin{array}{l}n \\
\hat{o} \\
0 \\
0\end{array}$ & సิ & $\begin{array}{l}\text { fo } \\
\stackrel{0}{0} \\
0\end{array}$ &  & $\begin{array}{l}\stackrel{ \pm}{a} \\
\stackrel{0}{0}\end{array}$ & $\begin{array}{l}n \\
\stackrel{n}{0} \\
0 \\
0\end{array}$ & $\begin{array}{l}\text { के } \\
\text { ठे. } \\
0\end{array}$ \\
\hline 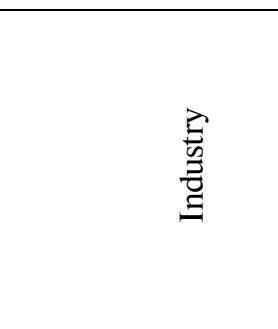 & & 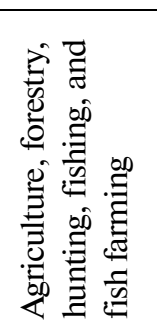 & 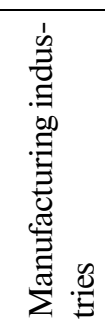 & 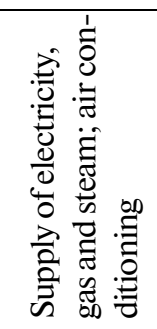 & 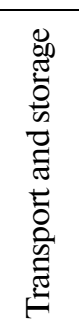 & 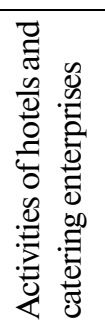 &  & 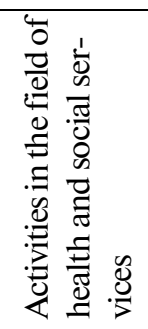 & 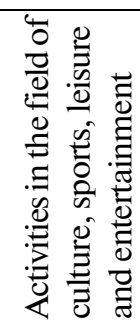 \\
\hline
\end{tabular}


Table 7. Interrelational income multiplier of qualification groups of workers

\begin{tabular}{|c|c|c|c|c|c|c|c|c|c|}
\hline Qualification group & 1 & 2 & 3 & 4 & 5 & 6 & 7 & 8 & 9 \\
\hline 1. Unqualified workers & 1.0117 & 0.0114 & 0.0113 & 0.0117 & 0.0116 & 0.0116 & 0.0113 & 0.0111 & 0.0105 \\
\hline $\begin{array}{l}\text { 2. Plant and machine operators, assemblers } \\
\text { and drivers }\end{array}$ & 0.0328 & 1.0319 & 0.0317 & 0.0326 & 0.0323 & 0.0323 & 0.0315 & 0.0308 & 0.0287 \\
\hline $\begin{array}{l}\text { 3. Qualified workers in manufacturing indus- } \\
\text { try, construction, transport }\end{array}$ & 0.0322 & 0.0309 & 1.0303 & 0.0319 & 0.0315 & 0.0314 & 0.0304 & 0.0294 & 0.0276 \\
\hline 4. Qualified agricultural workers & 0.0047 & 0.0044 & 0.0042 & 1.0046 & 0.0045 & 0.0045 & 0.0042 & 0.0040 & 0.0036 \\
\hline $\begin{array}{l}\text { 5. Workers in the service sector and trade, pro- } \\
\text { tection of citizens and property }\end{array}$ & 0.0344 & 0.0342 & 0.0343 & 0.0345 & 1.0344 & 0.0344 & 0.0342 & 0.0343 & 0.0329 \\
\hline $\begin{array}{l}\text { 6. Employees involved in the preparation and } \\
\text { execution of documentation, accounting and } \\
\text { maintenance }\end{array}$ & 0.0064 & 0.0063 & 0.0063 & 0.0064 & 0.0064 & 1.0064 & 0.0063 & 0.0062 & 0.0059 \\
\hline 7. Specialists of intermediate qualification level & 0.0313 & 0.0312 & 0.0314 & 0.0314 & 0.0312 & 0.0313 & 1.0314 & 0.0318 & 0.0310 \\
\hline 8. Specialists of the highest qualification level & 0.0677 & 0.0675 & 0.0676 & 0.0683 & 0.0677 & 0.0679 & 0.0675 & 1.0675 & 0.0641 \\
\hline 9. Managers & 0.0405 & 0.0396 & 0.0393 & 0.0404 & 0.0400 & 0.0400 & 0.0393 & 0.0387 & 1.0366 \\
\hline
\end{tabular}

sumption generated by income from excluding wages. This scenario allows us to measure the net effect of structural changes in the level of wages. Its implementation can lead, firstly, to an increase in the consumption of households provided with primary income from labor activity by $0.24 \%$ (45319 million rubles), all other things being equal, that is, while maintaining other final demand at the base level. In this case, the change in household consumption is taken as the initial impulse for the change in final demand. Secondly, the growth in the amount of outputs, initiated by the indicated structural shifts in wages, may amount to $0.06 \%$. It should be noted that the change in output by industry is multidirectional (Table 5), which is due to the different influence of consumer spending of different decile groups on industry output (see Table 1). Therefore, the sum of the absolute values of the deviations of the outputs from their basic values is $0.08 \%$ of the total of the basic outputs.

The growth in agricultural output is $0.2 \%$ (the coefficient of total requirements for agricultural products equal to 0.1256 for the 1st decile group and the coefficient equal to 0.0726 for the 10th decile group fully explain the growth in output of this industry with the redistribution of wages in favor of the 1st decile group), transactions with real estate by $0.24 \%$.

In some service industries, their decrease is observed: for hotels and public catering enterprises by $0.3 \%$, for health care and social services and activities in the field of culture, sports, leisure and entertainment, respectively, by 0.11 and $0.12 \%$. The gains in outputs obtained in this way also include the induced effect. In particular, the induced increase in wages for the 1 st decile group was $0.04 \%$ (adding to the growth by 1.5 times). Thus, even relatively modest structural shifts in the volume of wages by decile groups can lead to tangible structural and total changes in outputs.
Analysis of the relationship between the qualification structure of employment and household consumption. Similar calculations have been performed to assess the relationship between the qualification structure of employment and household consumption. Table 6 shows the coefficients of the total needs in the output of industries per unit of expenditure of consumer groups corresponding to various qualification groups of workers for the same industries that are given in Table 1.

Although there is a differentiation between the coefficients of the total needs of consumer groups corresponding to different qualification groups of workers, there is no such clear ranking as in the case of decile groups. Apparently, this circumstance is explained by not so clear differences in the level of income of qualification groups of workers, as well as by the difficulties in assessing the structure of consumption of workers assigned to certain qualification groups.

The multipliers of the interrelated incomes of the qualification groups of workers (Table 7) show practically the same response in the payroll of a qualification group, initiated by the consumer expenditures of various groups.

A slight variation is characteristic of the response to consumer spending by a group of managers: this indicator is usually lower than for other groups, which is natural, since this group includes the highest paid workers.

Conclusions. The analysis conducted confirms the thesis that the modern structure of the distribution of labor income between workers contributes to the increase in income inequality of the population. At the same time, an important confirmation was obtained that the existing structure of household consumption is the factor that hinders the decrease in the differentiation of the population by income. 
In terms of increasing labor income in all decile groups, the greatest return on growth in final demand is observed in industries with a high share of government spending in the structure of final consumption expenditures.

Calculations show that even insignificant structural shifts in the volume of wages by decile income groups of the population can lead to tangible structural and total changes in the volume of production and give an additional impetus to economic growth.

It should be especially noted that the growth in demand of low-income groups of the population to the greatest extent affects the incomes of high-income groups of the population. Thus, another argument is being formed in favor of the fact that the additional redistribution of primary income in favor of lowincome groups of the population allows not only reducing the level of differentiation by the level of income of the population, but also forming an additional impetus for reaching new levels of quality of life in the country.

\section{ACKNOWLEGMENTS}

The authors are grateful to V.V. Potapenko for help in preparing this article.

\section{CONFLICT OF INTEREST}

The authors declare that they have no conflicts of interest.

\section{REFERENCES}

1. A. Yu. Shevyakov, Inequality, Economic Growth, and Demography: The Unexplored Links (M-Studio, Moscow, 2009) [in Russian].

2. V. E. Gimpel'son, R. I. Kapelyushnikov, and A. V. Sharunina, "Low-paid jobs in the Russian labor market: is there a way out and where does it lead?," Ekon. Zh. Vyssh. Shk. Ekon. 22 (4), 489-530 (2018).

3. A. R. Sayapova and A. A. Shirov, Fundamentals of the Input-Output Method. Textbook for Universities (MAKS Press, Moscow, 2019) [in Russian]. https://doi.org/10.29003/m801.978-5-317-06263-7
4. M. Yu. Ksenofontov, A. A. Shirov, D. A. Polzikov, and A. A. Yantovskii, "Assessing multiplier effects in the Russian economy: input-output approach," Stud. Russ. Econ. Dev. 29, 109-115 (2018).

5. J. Bivens, Updated Employment Multipliers for the U.S. Economy (Economic Policy Institute, Washington, DC, 2019). https://www.epi.org/publication/updatedemployment-multipliers-for-the-u-s-economy/.

6. N. Lee and S. Clarke, Who Gains from High-Tech Growth? High-Technology Multipliers, Employment and Wages in Britain: SPRU Working Paper Series 2017-14 (University of Sussex Business School, Brighton, 2017).

7. H. Ito and M. Doi, "Endogenizing consumption in the input-output model: theory and application," Rev. Urban Reg. Dev. Stud. 20 (2), 151-166 (2009).

8. A. E. Steenge, "On the complete instability of empirically implemented dynamic Leontief models," Econ. Syst. Res. 2 (1), 3-16 (1990).

9. A. E. Steenge, A. Carrascal Incera, and M. Serrano, "Income distributions in multi-sector analysis; Miyazawa's fundamental equation of income formation revisited," Struct. Change Econ. Dyn. 53, 377-387 (2020).

10. A. R. Sayapova, "Relationship between the development of tools and analytical capabilities of the inputoutput method," Probl. Prognozirovaniya, No. 1, 5969 (2021). https://doi.org/10.47711/0868-6351-184-59-69

11. R. E. Miller and P. D. Blair, Input-Output Analysis. Foundations and Extensions, 2nd ed. (Cambridge University Press, Cambridge, 2009).

12. K. Miyazawa, Input-Output Analysis and the Structure of Income Distribution (Springer-Verlag, New York, 1976).

13. F. Gantmacher, The Theory of Matrices (American Mathematical Society, Providence, RI, 2000; Fizmatlit, Moscow, 2004).

14. E. A. Edinak and A. A. Shirov, "Assessment of the relationship between the qualification structure of employment and household consumption using inputoutput tables," Stud. Russ. Econ. Dev. 32, 593-602 (2021).

Translated by S. Avodkova 